\title{
PENGETAHUAN IBU HAMIL PRIMIGRAVIDA TENTANG PERAWATAN PAYUDARA
}

\section{Knowledge Of Primigravida Pregnant About Breast Care}

Rofik Darmayanti

Diploma III, Akbid Dharma Husada Kediri, Kediri, Indonesia

Email: rofik.darmayanti@gmail.com

\section{N F O A R T I K E L}

\section{Sejarah artikel:}

Menerima2 September 2019

Revisi 25 September 2019

Diterima 02 Oktober 2019

Online 10 Oktober 2019

Kata kunci:

Pengetahuan

hamil Primigravida

Perawatan Payudarah

Keywords:

Attitude

Pregnant

Breast Care

\section{ABSTRAK}

Abstrak: Perawatan payudara yang baik pada ibu hamil diperlukan suatu pengetahuan yang baik agar selama perawatan tersebut dapat dilakukan dengan benar, adapun ibu hamil yang tidak melakukan perawatan payudara maka akan terjadi kurangnya kebersihan pada payudara, bedungan ASI, pengeluaran ASI tidak lancar. Oleh sebab itu, Pelaksanaan perawatan payudara sangat diperlukan, namun banyak dari ibu-ibu hamil yang tidak melakukan perawatan payudara di karenakan oleh pengetahuan atau informasi yang kurang. Tujuan Penelitian ini adalah untuk mengetahui pengetahuan ibu hamil primigravida tentang perawatan payudara di Desa Joho Kecamatan Wates Kabupaten Kediri. Penelitian ini mengunakan Metode diskriptif. Populasinya adalah semua ibu hamil primigravida di desa Joho Kecamatan Wates Kabupaten Kediri sebanyak 15 orang. Teknik samling menggunakan total sampling. Variabel penelitian ini menggunakan variable tunggal yaitu pengetahuan ibu primigarvida tentang perawatan payudarah. Diharapkan tenaga kesehatan dan ibu hamil meningkatkan informasi tentang perawatan payudara. Dari hasil penelitian diketahui yang responden pengetahuan baik 7 orang $(47 \%)$, yang berpengetahuan cukup 8 orang (53\%).

\section{ABSTRACT}

Well breast care for pregnant is needed a god knowledge to do a true treatment, there is a pregnant don't breast care so the expenditure is not smooth. Therefore breast care is very important, but the pregnant don't breast care because the knowledge and information is less. The purpose of the research is to know knowledge primigravida pregnant about breast carebefore at Joho Village Wates District Kediri Regency. The population is all primigravida pregnant women in the village of Joho, Wates Subdistrict, Kediri Regency, as many as 15 people. The samling technique uses total the Dependent variable is the knowledge of primigravida pregnant women about breast care. The data collection by using questionnairesThe result of the reseach know that have a good knowledge is seven people (47\%), that less knowledge is eight people (53\%). The conclusion of the reseach, there is a differences primigravida pregnant about breast care So this scientific paper, usefull for many society in the future it is expected to be even better. 


\section{PENDAHULUAN}

Ketika wanita sedang hamil banyak yang dipersiapkan untuk kelahiran dan untuk selama melahirkan. Salah satunya merupakan persiapan menyusui, dan payudara pun harus dipersiapkan saat masih dalam masa kehamilan. Pertama yang harus dipersiapakan yaitu perawatan payudara sebab untuk menyiapkan diri ketika nanti akan memberikan air susu ibu (ASI). Hal ini harus dan wajib dilakukan selama kehamilan atau sedini mungkin (Rahmawati, 2017). Sebagian besar para ibu hamil tidak melakukan perawatan payudara karena kurangnya pengetahuan dalam perawatan payudara itu sendiri, kurangnya informasi tentang perawatan payudara seperti puting susu tidak menonjol atau datar karena keadaan buah dada, khususnya puting susu merupakan salah satu faktor yang menentukan keberhasilan proses laktasi, kurangnya kesadaran para ibu akan pentingnya perawatan payudara selama kehamilan, tidak adanya dukungan dari keluarga untuk melakukan perawatan payudara sejak masa kehamilan, dan belum diberikan pendidikan kesehatan oleh petugas kesehatan. Ibu-ibu membutuhkan bantuan dan informasi serta dukungan dari segala pihak agar merawat payudara pada saat hamil untuk mempersiapkan ASI. Sehingga dapat menambah keyakinan bahwa mereka dapat menyusui bayinya dengan baik dan mengetahui fungsi serta manfaat perawatan payudara pada saat hamil. Selama kehamilan payudara akan membengkak dan daerah sekitar puting susu warnanya akan lebih gelap. Keadaan payudara yang membengkak ini, payudara menjadi mudah teriritasi bahkan mudah luka. Ibu-Ibu hamil tidak akan kesulitan dalam pemberian ASI bila sejak awal telat mengetahui bagaimana perawatan payudarah yang tepat dan benar. Ibu hamil yang tidak melakukan perawatan payudara selama kehamilan dan perawatan tersebut hanya dilakukan pasca persalinan, maka akan menimbulkan beberapa permasalahan seperti ASI tidak keluar, produksi ASI sedikit dan tidak cukup dikonsumsi bayi, dan payudara kotor (Indrasari, 2016). Berdasarkan survey di Indonesia tahun 2009 307/100 ribu ibu hamil tidak melakukan perawatan payudara. Dari angka tersebut telah mengalami sebuah perubahan atau penurunan pada tahun 2010 dari angka tersebut menjadi 290/100 ribu ibu tidak melakukan perawatan payudara selama hamil. Sementara hasil survei tahun 2011 menyebutkan di Indonesia sebesar228/100 ribu ibu hamil yang tidak melakukan perawatan payudara selama kehamilan ( Depkes RI, 2011). Hasil survei ditahun 2009 di provinsi Jawa Timur tercatat $70,4 \%$ ibu hamil tidak melakukan perawatan payudara selama hamil. Namun masih ada 29,6\% ibu hamil yang melakukan perawatan payudara. Di provinsi Jawa Timur pada tahun 2010 prosentase ibu hamil yang melakukan perawatan payudara 18,8\%. Sedangan tahun 2010 yang tidak melakukan perawatan payudara selama hamil 83,2\%.Berdasarkan data di Kabupaten Kediri jumlah ibu hamil yang melakukan perawatan payudara masih kurang dikarenakan mereka belum mengerti tentang fungsi perawatan payudara. Pada tahun 2009-2010 ialah sekitar $25 \%$ ibu hamil yang melakukan perawatan payudara, sedangkan pada tahun 2011 terjadi peningkatan menjadi $40 \%$ ibu hamil yang telah melakukan perawatan payudara. Berarti masih ada sekitar $60 \%$ ibu payudara selama masa hamil ( Erna S.W, 2015).Sebagai tenaga kesehatan harus melakukansuatu kepedulian terhadap ibu hamil untuk melakukan perawatan payudara guna mempersiapkan dan mencukupi kebutuhan ASI. Dengan memberikan pendidikan dan penyuluhan tentang perawatan payudara. Dengan begitu ibu hamil dapat melakukan perawatan payudara seperti membersihkan puting susu dengan benar maka akan terhindar dari infeksi dan menghindari penyulit saat menyusui seperti puting lecet, ASI tidak lancar berproduksi maupun pembengkakan payudara. Dengan melakukan perawatan payudara pada ibu hamil ini merupakan sebuah solusi untuk mengatasi berbagai komplikasi masalah yang terjadi.

\section{METODE PENELITIAN}

Desain penelitian ini merupakan penelitian desain deskriptif..

Rancangan penelitian yang akan digunakan dalam penelitian ini adalah penelitian dengan menggunakan pendekatan Cross Sectional. penelitianCross Sectional adalah jenis penelitian yang menekankan waktu pengukuran atau observasi data variabel hanya satu kali pada satu saat. Variabel yang digunakan adalah variable

Jurnal KebidananVol.8 No. 2 Oktober 2019 | 117 
tunggal yaitu pengetahuan ibu hamil

primigravida tentang perawatan payudara

\section{HASIL PENELITIAN}

Distribusi Karakteristik Responden

a. Karakteristik Responden Berdasarkan Usia

Table I. 1 Karakteristik Responden Berdasarkan Usia Ibu Hamil Primigravida

\begin{tabular}{ccc} 
Umur & Frekuensi & Prosentase (\%) \\
\hline$<20$ tahun & 1 & 7 \\
\hline $20-35$ tahun & 14 & 93 \\
\hline$>35$ tahun & 0 & 0 \\
\hline Jumlah & 15 & 100
\end{tabular}

Berdasarkan tabel I.I diketahui bahwa paling banyak responden berumur 20-35 tahun sebanyak 14 orang ( $93 \%$ ) dan paling sedikit yang berumur $<35$ tahun sebanyak 0 orang $(0 \%)$

b. Karakteristik Responden Berdasarkan Pendidikan

Table I. 2 Karakteristik Responden Berdasarkan Pendidikan Ibu Hamil Primigravida

\begin{tabular}{ccc} 
Pendidikan & Frekuensi & Prosentase (\%) \\
\hline Tidak tamat SD & 0 & 0 \\
\hline SD & 1 & 7 \\
\hline SMP & 4 & 27 \\
\hline SMA & 8 & 53 \\
\hline PT & 2 & 13 \\
\hline Jumlah & 15 & 100
\end{tabular}

Berdasarkan tabel I. 2 diketahui bahwa paling banyak responden berpendidkan SMA 8 orang (53\%) dan paling sedikit berpendidikan SD sebanyak 1 orang $(7 \%)$.

c. Karakteristik Responden Berdasarkan Pekerjaan

Table I. 3 Karakteristik Responden Berdasarkan Pekerjaan Ibu Hamil Primigravida

\begin{tabular}{ccc} 
Pekerjaan & Frekuensi & Prosentase (\%) \\
\hline Tidak Bekerja & 10 & 67 \\
\hline Wiraswasta & 3 & 20 \\
\hline PNS & 2 & 13 \\
\hline Jumlah & 15 & 100
\end{tabular}

Berdasarkan tabel 1.3 Diketahui bahwa paling banyak responden tidak bekerja 10 orang (67\%) dan yang paling sedikit responden PNS sebanyak 2 orang (13\%). 


\section{d. Karakteristik Responden Berdasarkan Sumber Informasi}

Table I.4 Karakteristik Responden Berdasarkan Sumber Informasi tentang Perawatan

Payudara

\begin{tabular}{ccc} 
Sumber Informasi & Frekuensi & Prosentase (\%) \\
\hline Tenaga Kesehatan & 4 & 27 \\
\hline Tv/Radio/Internet & 8 & 53 \\
\hline Orang lain & 2 & 13 \\
\hline Buku & 1 & 7 \\
\hline Jumlah & 15 & 100
\end{tabular}

Berdasarkan tabel I.4 diketahui bahwa paling banyak responden yang mendapatkan informasi dari tv atau radio atau internet sebanyak 8 orang
(53\%) dan yang paling sedikit mendapat informasi dari buku 1 orang (7\%)

Data Khusus

Table I. 5 Distribusi Frekuensi Pengetahuan Ibu Hamil Primigravida Tentang Perawatan Payudara

\begin{tabular}{cccc} 
No & Pengetahuan & Frekuensi & Prosentase (\%) \\
\hline 1. & Baik & 7 & 47,00 \\
\hline 2. & Cukup & 8 & 53,00
\end{tabular}

\section{PEMBAHASAN}

Pengetahuan Ibu Hamil PrimigravidaTentang Perawatan Payudara

Berdasarkan Tabel 1.5 diketahui pengetahuan ibu hamil primigravida tentang perawatan payudara di Desa Joho Kecamatan Wates Kabupaten sebagian besar dalam kategori baik yaitu sebanyak di dapatkan 7 (47\%) responden ibu hamil primigravida, 8 responden (53\%) dalam kategori cukup, dan tidak ada responden $(0 \%)$ dalam kategori kurang.

Pengetahuan adalah merupakan hasil "Tahu" dan ini terjadi setelah orang mengadakan penginderaan terhadap suatu objek tertentu. Penginderaan terhadap obyek terjadi melalui panca indra manusia yakni penglihatan, pendengaran, penciuman, rasa dan raba dengan sendirinya. Pada waktu penginderaan sampai menghasilkan pengetahuan tersebut sangat dipengaruhi oleh intensitas perhatian persepsi terhadap obyek. Sebagian besar pengetahuan manusia diperoleh dari mata dan telinga

( Wawan\& Dewi, 2010 : 11).

Dengan semakin banyak responden memanfaatkan indera yang di milikinya sebagai proses belajar dan mendapatkan pengalaman, maka akan bertambah banyak pula pengetahuan yang akan mereka peroleh, dan sebagian responden sudah mengetahui tentang perawatan payudara. Pengetahuan tersebut sangat erat kaitan nya dengan pengalaman dan sosial budaya, dimana dengan pengetahuan yang baik seseorang mampu memahami peraturan adat istiadat setempat sehingga dapat menaati peraturan yang ada. Biasanya di suatu daerah dalam hal kesehatan terdapat pantangan tertentu, namun pada orang yang berpengetahuan baik, seseorang mampu membedakan hal yang boleh ditiru dan yang tidak boleh ditiru.

Pengetahuan ibu hamil itu sendiri dipengaruhi oleh beberapa faktor salah satunya adalah pendidikan responden. Berdasarkan hasil penelitian disebutkan pendidikan responden di Desa Joho Kecamatan Wates Kabupaten Kediri. Dari 15 responden pendidikan ibu hamil primigravida berbeda-beda mulai dari SD sampai dengan PT. Dari 1 responden berpendidikan SD $(7 \%) .4$ responden berpendidikan SMP $(27 \%), 8$ responden berpendidikan SMA (53 \%) dan 2 Responde berpendidikan PT( 13\%).

Pendidikan berarti bimbingan yang diberikan seseorang terhadap perkembangan orang lain menuju kearah cita-cita tertentu yang menentukan manusia untuk berbuat dan menangis kehidupan untuk mencapai keselamatan dan kebahagian. pendidikan diperlukan untuk mendapatkan informasi Jurnal KebidananVol.8 No. 2 Oktober 2019 | 119 
misalnya hal-hal yang menunjang kesehatan sehingga dapat meningkatkan kualitas hidup. (Wawan \& Dewi, 2016:16)

Sehingga semakin tinggi pendidikannya maka semakin banyak pengetahuan yang dimiliki, juga akan semakin mudah untuk memperoleh informasi. Sebaliknya pendidikan yang rendah akan menghambat perkembangan seseorang terhadap nilai-nilai yang harus diperkenalkan sebagai proses perubahan tingkah laku dan pola berfikir.

Pengetahuan sangat erat kaitannya dengan pendidikan dimana seseorang yang berpendidikan tinggi pastinnya semakin luas pengetahuannya, namun bagi yang berpendidikan rendah belum berarti berpengetahuan rendah.

Berdasarkan Tabel I.1 yang berkaitan dengan umur responden sebagian besar berumur 20-35 tahun sebanyak 14 orang ( $93 \%$ ) , yang berumur 20 tahun sebanyak 1 orang ( $7 \%)$, tidak ada responden $(0 \%)$ yang berumur $>35$ tahun.

Menurut elisabeth $\mathrm{BH}$ yang dikutip dari Nursalam (2003), Usia adalah umur individu yang terhitung mulai saat dilahirkan sampai berulang tahun. Sedangkan menurut Hunclok (1998) semakin cukup umur, tingkat kematangan dan kekuatan seseorang akan lebih matang dalam berfikir dan bekerja.

Dari segi kepercayaan masyarakat seseorang yang lebih dewasa dipercaya dari orang yang belum tinggi kedewasaannya. Hal ini akan sebagai dari pengalaman dan kematangan jiwa. Selain itu sehubungan dengan bertambahnya umur yaitu semakin cukup umur maka akan berpengaruh pada kemampuan seseorang untuk berfikir terhadap informasi yang diterimanya.

Dari kuesioner nomer 1 mengenai pengertian perawataan payudara dapat diketahui bahwa dari 15 responden (100\%) hampir dapat menjawab pertanyaan dengan benar.

\section{SIMPULAN}

Pengetahuan ibu hamil primigravia tentang perawatan payudara menunjukkan pengetahuan yang baik yakni sebanyak 7 responden (47\%) dan yang memiliki pengetahuan cukup adalah 8 responden $(53 \%)$
Perawatan Payudara adalah suatu tindakan untuk merawat payudara terutama pada masa nifas (masa menyusui) untuk memperlancar pengeluaran ASI. Perawatan payudara sangat penting dilakukan selama hamil sampai masa menyusui. Hal ini dikarenakan payudara merupakan satu-satunya penghasil ASI yang merupakan makanan pokok bayi baru lahir sehingga harus dilakukan sedini mungkin (Walyani \& Purwoastuti,2017 : 27)

Oleh karena itu masih banyak ibu hamil yang belum memahami bahwa perawatan payudara waktu kehamilan anatara lain bertujuan untuk menjaga kebersihan payudara terutama kebersihan puting susu, melenturkan dan menguatkan puting susu sehingga memudahkan bayi untuk menyusu, merangsang kelenjarkelenjar air susu sehingga ASI banyak dan lancar.

Dari kuesioner no 20 tentang cara perawatan payudara selama kehamilan dapat diketahui bahwa mereka belum mengetahuinya. Terbukti dari 15 responden hanya 7 responden $(46,6 \%)$ yang dapat menjawab dengan benar. kemungkinana besar bagi responden perawatan payudara tidak begitu bermanfaat bagi ibu hamil.

Manfaat perawatan payudara yaitu menjaga ke bersihan payudara terutama kebersihan puting susu, melenturkan dan menguatkan puting susu sehingga memudahkan bayi untuk menyusu, merangsang kelenjar-kelenjar air susu sehingga produksi ASI banyak dan lancar dan dapat mendeteksi kelainan-kelainan payudara secara dini dan melakukan upaya untuk mengatasinya serta mempersiapkan mental (psikis) ibu untuk menyusui (Saryono \& Pramitasari, 2014: 51).

Hal tersebut sangat kurang efisien, seharusnya ibu hamil tersebut mencari informasi atau menggali informasi lebih luas baik dari orang lain maupun media lainnya. Sebab begitu banyak manfaat perawatan payudara bagi ibuibu hamil tersebut.

Penelitian ini masih memiliki banyak kekurangan dalam penulisan, penyusunan dan proses penelitian, sehingga diharapkan penelitian selanjutnya dapat lebih baik dari penelitian sebelumnya. Bagi Tempat Penelitian 
Dari hasil ini dapat menjadi masukan bagi tempat penelitian untuk meningkatkan pemberian informasi pada ibu hamil primigravida tentang perawatan payudara oleh petugas kesehatan.Bagi pembaca Hasil dari penelitian ini dapat menjadi infromasi yang baik

\section{REFERENSI}

Ariani, A. Putri. 2014. Aplikasi Metodologi Penelitian Kebidanan Dan Kesehatan Reproduksi. Yogyakarta : Nuha Medika

Astutik, R. Y.2014. Payudara Dan Laktasi.Jakarta : Salemba Medika

Bandiyah, Siti. 2009. Kehamilan, Persalinan Dan Gangguan Kehamilan. Yogyakarta : Nuha Medika.

Dorland,W.A. Newman. 2012. Kamus Kedokteran Dorland; Edisi 28, Jakarta: Buku Kedokteran EGC

Gavinov \& Soemantri.2016.Sistem Informasi Kesehatan.Yogyakarta : Nuha Medika

Hidayat, A. A. 2014. Metode pnelitian Kebidanan dan Teknik Analisis. Jakarta : Salemba Medika

Hamdani, M. 2013. Promosi Kesehatan Untuk Kebidanan.Jakarta : CV Trans Info Media.

Maulana, Heri D.2012.Promosi Kesehatan.Jakarta : Buku Kedoktran EGC

Notoatmodjo, S.2010.Metode penelitian kesehatan.Jakarta : Bina Cipta

: Bina Cipta 2016.Metode penelitian kesehatan.Jakarta

Prawirohardjo, Sarwono. 2014. Ilmu Kebidanan.Jakarta : Bina Pustaka

Prasetyono, S. D.2012. Buku Pintar ASI Eksklusif. Yogyakarta : Diva Press

Saryono \& Pramitasari, R. Dyah. 2014. Perawatan Payudara. Yogyakarta : Nuha Medika

Sutanti, A. V. 2018. Asuhan Kebidanan Nifas Dan Menyusui.Yogyakarta : Pustaka Baru Press

Sugiyono, 2017. Statistika untuk penelitian. Bandung : Alfabeta

Setiawan, A. \& Saryono. 2011. Metodologi Penelitian D III, D IV, S1, Dan S2. Yogyakarta : Nuha medika dan dapat disebar luaskan untuk meningkatkan pengetahuan. Bagi InstitusiDiharapkan penelitian ini dapat menjadi sumber informasi yang dapat dikembangkan oleh peneliti selanjutnya sehingga dapat dianalisi lebih mendalam

Waryana.2016.Promosi Kesehatan, Penyuluhan, Dan Pemberdayaan Masyarakat. Yogyakarta : Nuha Medika

Wawan \& M. Dewi. 2016. Pengetahuan, Sikap Dan Perilaku Manusia. Yogyakarta: Nuha Medika

Walyani, E. S. \& Purwoastuti, E.2017. Asuhan Kebidanan Masa Nifas Dan Menyusui.Yogyakarta : Pustaka Baru Press

Weni, Kristiyanasari. 2011. ASI ,Menyusui dan SADARI.Yogyakarta : Nuha Medika

Indrasari, Nelly.2016. Hubungan Pengetahuan Ibu Hamil Dengan pelaksanaan perawatan payudara. Journal. [ online ] diakses pada tanggal 19 Maret 2019. https://ejurnal.poltekkestik.ac.id/index.php/JKEP/article/view/335

Rahmawati, A. E Realita, F.2016.Pengetahuan Ibu hamil tentang perawatan payudara. Journal. [ online ] diakses pada tanggal 18 Maret 2019.

http://ejurnal.stikeseub.ac.id/index.php/jkeb/article/vie wFile/217/207

Rachmawati, M. \& Puspitasari, T.2017. Tingkat Pengetahuan ibu primigravida tentang perawatan payudara. Journal. [online] diakses pada tanggal 9 Maret 2019.

http://www.ejournalaipkema.or.id/aipkema/index.php/jrki/article/downloa $\underline{\mathrm{d} / 2 / 12}$

Wati, E. S.2015. A study knowledge About pregnancy breast careat the BPS EttydiFakultas Ilmu Kesehatan Universitas Nusantara PGRI Kediri Vol. 2. No.1.April 2015

Jurnal KebidananVol.8 No. 2 Oktober 2019 | 121 
